Pacific Journal of Mathematics

THE EVOLUTION OF BOUNDED LINEAR FUNCTIONAL S 


\title{
THE EVOLUTION OF BOUNDED LINEAR FUNCTIONALS WITH APPLICATION TO INVARIANT MEANS
}

\author{
H. KHARAGHANI
}

Let $S$ be a topological semigroup and let $X$ be a left translation invariant, left introverted closed subspace of $C B(S)$. Let $m$ and $\bar{\mu}$ be elements of $X^{*}$, where $\bar{\mu}(f)=\int f d \mu$ for $f$ in $C B(S)$ and $\mu$ is a measure on $S$ which lives on a suitable set. It is shown that the evolution and convolution of $m$ and $\bar{\mu}$ coincide. The same argument carries over to prove that if $X \subset W(S)$, then the evolution and convolution of $m$ and $n$ in $X^{*}$ are the same (a known result). The topological invariance of invariant means on $X^{*}$ is discussed.

1. Preliminaries. Let $S$ be a topological semigroup with separately continuous multiplication and $C B(S)$ the Banach space, under supremum norm of bounded real continuous functions on $S$. For each $s$ in $S$, define the left and right translation operators on $C B(S)$ by $\left(l_{s} f\right)(t)=$ $f(s t)$ and $\left(r_{s} f\right)(t)=f(t s)$ for all $t$ in $S, f$ in $C B(S)$. The subspace $X$ of $C B(S)$ is called left (right) introverted, if for each $m$ in $X^{*}$ the function $s \rightarrow f * m(s)=m\left(l_{s} f\right)\left(s \rightarrow m * f(s)=m\left(r_{s} f\right)\right)$ is in $X . \quad W(S)$ denotes the subspace of $C B(S)$ consisting of weakly almost periodic functions, i.e., the functions $f$ such that the set $\left\{r_{s} f: s \in S\right\}$ is conditionally weak compact. $L U C(S)(W L U C(S))$ is the subspace of $C B(S)$ consisting of (weakly) left uniformly continuous functions on $S$, i.e., the functions $f$ such that the map $s \rightarrow l_{s} f$ is norm (weak) continuous. $M_{o}(S)(M(S))$ denotes the linear space of all real valued signed Baire (regular Borel) measures on $S$. The mapping $T: C B(S) \rightarrow M^{*}(S)$ is the natural embedding of $C B(S)$ into $M^{*}(S)$ defined by $(T f)(\mu)=\int f d \mu$ for $f$ in $C B(S)$ and $\mu$ in $M(S)$. Following Granirer [4] $\sigma\left(C B(S), M_{\sigma}(S)\right)=$ $\sigma\left(C, M_{\sigma}\right)$ denotes the weakest topology on $C B(S)$ which makes all linear functionals on $C B(S)$ of type $\int f d \mu$ for $\mu$ in $M_{\sigma}$ continuous.

For $\mu$ in $M_{\sigma}(S)$ or in $M(S)$ and $f$ in $C B(S)$ let $\mu * f(t)=\int r_{t} f d \mu$, $f^{*} \mu(t)=\int l_{t} f d \mu$ for any $t$ in $S$.

For $\mu$ in $M_{\sigma}(S)$ or in $M(S), \bar{\mu}$ denotes the functional in $C B^{*}(S)$ defined by $\bar{\mu}(f)=\int f d \mu$ for $f$ in $C B(S)$.

2. The main theorem. Before stating the main theorem we need the following lemma.

Lemma 2.1. Let $S$ be a topological semigronp. For $f$ in $C B(S)$ 
and $M \geqq 0$ let

$$
B_{M}(f)=\left\{f * m: m \text { in } X^{*} \text { and }\|m\| \leqq M\right\} .
$$

(i) $B_{M}(f)$ is pointwise compact.

(ii) If $S$ is locally compact and $f$ is in $W L U C(S)$ then $T\left(B_{M} F\right)$ is $\sigma\left(M^{*}(S), M(S)\right)$-compact.

(iii) If $S$ is a completely regular $D$-space (for definition see [3]), and $f$ is in $L U C(S)$, then $B_{M}(f)$ is $\sigma\left(C, M_{o}\right)$-compact.

(iv) If $f$ is in $W(S)$, then $B_{M}(f)$ is weak compact.

(v) In each case (i)-(iv) the topology of pointwise convergence and the indicated topology coincide on $B_{M}(f)$.

Proof. (i) By Alaoglu's theorem the set $\left\{m: m\right.$ in $X^{*}$ and $\left.\|m\| \leqq M\right\}$ is weak * compact. Using this one can easily show that $B_{M}(f)$ is pointwise compact.

(ii) Since $f$ is in $W L U C(S)$ and $\|f * m\| \leqq M\|f\|, B_{M}(f)$ is a norm bounded subset of $C B(S)$. Therefore this follows from [Glicksberg 3, Theorem 1.1] and preceeding part.

(iii) Since

$$
\begin{aligned}
\left|f * m(s)-f * m\left(s_{0}\right)\right| & =\left|m\left(l_{s} f\right)-m\left(l_{s_{0}} f\right)\right| \leqq\|m\|\left\|l_{s} f-l_{s_{0}} f\right\| \\
& \leqq M\left\|l_{s} f-l_{s_{0}} f\right\|
\end{aligned}
$$

for each $m$ with $\|m\| \leqq M$ and the map $s \rightarrow l_{s} f$ is norm continuous, one deduce that $B_{M}(f)$ is an equicontinuous family of functions on $S$. By [4, Theorem 1 (a)] it follows that $B_{M}(f)$ is $\sigma\left(C, M_{\sigma}\right)$-conditionally compact. By part (i) $B_{M}(f)$ is pointwise compact and therefore $B_{M}(f)$ is $\sigma\left(C, M_{\sigma}\right)$-closed. Hence $B_{M}(f)$ is $\sigma\left(C, M_{\sigma}\right)$-compact.

(iv) This follows from [8, remark (a) after Theorem 3.3].

(v) This follows from [13, 3.8 (a), P. 61] and part (i).

Now the main theorem of the paper can be proved.

THEOREM 2.2. Let $S$ be a topological semigroup and $X$ a left translation invariant, left introverted closed subspace of $C B(S)$.

(i) If $S$ is locally compact and $X \subset W L U C(S)$, then for each $\mu$ in $M(S), \mu * X \subset X$ and furthermore, for each $m$ in $X^{*},\langle\bar{\mu}, f * m\rangle=$ $\langle\mu * f, m\rangle$ for all $f$ in $X$.

(ii) If $S$ is a completely regular $D$-space and $X \subset L U C(S)$, then for each $\mu$ in $M_{\sigma}(S), \mu * X \subset X$ and furthermore, for each $m$ in $X^{*}$ $\langle\bar{\mu}, f * m\rangle=\langle\mu * f, m\rangle$ for all $f$ in $X$.

(iii) If $X \subset W(S)$, then for each $n$ in $X^{*}, n * X \subset X$ and furthermore, $\langle n, f * m\rangle=\langle n * f, m\rangle$ for each $m$ in $X^{*}$ and $f$ in $X$.

Proof. (i) Let $f$ be in $X$ and $\mu$ in $M(S)$. Define the functional 
$\psi$ on $X^{*}$ by $\psi(m)=\int f * m d \mu$ for $m$ in $X^{*}$. It is easy to see that $\mu$ is linear. We will show that $\psi$ is weak $*$ continuous on each ball $N_{M}=\left\{m: m\right.$ in $X^{*}$ and $\left.\|m\| \leqq M\right\}$. To see this let $m_{0}$ be a point in $N_{M}$ and $\left\{m_{\alpha}\right\}$ a net in $N_{M}$ converging weak $*$ to $m_{0}$. Then $f * m_{\alpha}$ converges to $f * m_{0}$ pointwise on $S$. Let $B_{M}(f)$ be as defined in Lemma 2.1. Hence by Lemma 2.1. (v) the pointwise topology and $\sigma\left(M^{*}(S)\right.$, $M(S)$ ) coincide on $B_{M}(f)$. Therefore $\int f * m_{\alpha} d \nu \rightarrow \int f * m d \nu$ for each $\nu$ in $M(S)$. In particular

$$
\psi\left(m_{\alpha}\right)=\int f * m_{\alpha} d \mu \longrightarrow \int f * m d \mu=\psi(m) .
$$

Therefore it follows from [14, Corollary A.12, p. 89] that $\psi$ is nothing but an evaluation functional. That is, there exists $g$ in $X$ such that $m(g)=\int f * m d \mu$ for each $m$ in $X^{*}$. For each $s$ in $S$, let $m=Q(s)$ be the evaluation functional at $s$ in the above identity. Then $Q(s) g=$ $g(s)=\int r_{s} f d \mu=\mu * f(s)$. This implies that $\mu * f$ is in $X$ and furthermore, $m(\mu * f)=\langle\mu * f, m\rangle=\int f * m d \mu=\int\langle\bar{\mu}, f * m\rangle$. This completes the proof.

(ii) The proof is similar to preceeding part.

(iii) Let $f$ be in $X$. For $n$ in $X^{*}$ define the functional $\psi$ on $X^{*}$ by $\psi(m)=n\left(m_{l} f\right)$ for $m$ in $X^{*}$. By an argument similar to part one and using Lemma 2.1 (v) one can show that $\psi$ is an evaluation functional on $X^{*}$. The rest follows as in part (i).

REMARKS. (a) If in addition to hypothesis of Theorem 2.2 (i), $X$ is also a $c^{*}$-subalgebra of $C B(S)$, then Theorem 2.2 (i) reduces to a result of Milnes [9, Lemma 3.3].

(b) It is possible to give a proof of Theorem 2.2 (ii) by a method similar to that of Granirer in [4, Lemma 3 and Theorem 4, p. 20].

(c) Let $S$ be a topological semigroup and let $X$ be a translation invariant, left and right introverted subspace of $C B(S)$ such that $\langle n, f * m\rangle=\langle n * f, m\rangle$ for each $m$ and $n$ in $X^{*}$ and $f$ in $X$. Let $f$ be in $X$, then using Alaoglu's theorem and assumption it is easy to see that the set $\left\{f * m: m\right.$ in $X^{*}$ and $\left.\|m\| \leqq M\right\}$ is weak compact for each nonnegative real $M$. This shows that $f$ is in $W(S)$. Hence $X \subset W(S)$.

(d) Theorem 2.2 (iii) and Preceeding remark is due to Pym [11, Theorem 4.2]. Our proof here is easier and different from that of Pym.

(e) Theorem 2.2 (iii) implies that $W(S)$ is a right introverted subspace of $C B(S)$. By an argument similar to preceeding remark (c) one can show that for each nonnegative $N$, the set $\left\{n_{r} f: n\right.$ in $X^{*}$ and $\|n\| \leqq N\}$ and hence the set $\left\{l_{s} f: s\right.$ in $\left.S\right\}$ is weak compact. This 
in particular implies the known result that for $f$ in $C B(S),\left\{l_{s} f: s\right.$ in $S\}$ is conditionally weak compact if $\left\{r_{8} f: s\right.$ in $\left.S\right\}$ is conditionally weak compact.

(f) The proof of Theorem 2.2 (i) and (ii) is independent of the topological structure of $S$, but it depends on the topological structure of the set on which the measure $\mu$ "lives" (see [4] for definition).

3. Applications. A. Invariant means on locally compact semigroups. Let $S$ be a topological semigroup and $X$ a closed subspace of $C B(S)$ containing the constant function $1 . m$ in $X^{*}$ is called a mean if $\|m\|=m(1)=1$. If in addition $X$ is left translation invariant, the mean $m$ is called left invariant if $m\left(l_{s} f\right)=m(f)$ for all $s$ in $S$ and all $f$ in $X$. Let $S$ be a locally compact (resp. completely regular $D$-space) semigroup and $X \subset C B(S) . \quad X$ is called topological left translation invariant if $\mu * X \subset X$ for each $\mu$ is $M(S)$ (resp. $M_{o}(S)$ ). The mean $m$ on $X$ is topological left invariant if $m(\mu * f)=m(f)$ for each probability measure $\mu$ in $M(S)\left(\operatorname{resp} . M_{\sigma}(S)\right.$ ).

CoRollary 3.1. (i) Let $S$ and $X$ be as in Theorem 2.2 (i), then $X$ is topological left translation invariant and the mean $m$ on $X i s$ left translation invariant iff it is topological left invariant.

(ii) Let $S$ and $X$ be as in Theorem 2.2(ii), then $X$ is topological left translation invariant and the mean $m$ on $X$ is left invariant iff it is topological left invariant.

Proof. (i) The topological left invariance of $X$ is a part of Theorem 2.2 (i). If $m$ is topological left invariant, then clearly it is left invariant. Suppose $m$ is left invariant. By Theorem 2.2 (i) $\langle\mu * f, m\rangle=m(\mu * f)=\langle\bar{\mu}, f * m\rangle=\int f * m d \mu=\int m\left(l_{s} f\right) d \mu(s)=m(f)$ for each probability measure $\mu$ in $M(S)$ and each $f$ in $X$.

(ii) Proof is similar to part (i).

REMARKs. 1. If in addition to the hypothesis of Corollary 3.1 (i), $X$ is also a $c^{*}$-subalgebra of $C B(S)$, then Corollary 3.1 reduces to a result of Milnes [9, Corollary 3.3].

2. If $S$ is a locally compact group Corollary 3.1 (i) reduces to a more general version of results of Namioka [10], Hulanicki [7] and Greenleaf [5, Lemma 2.2.2].

3. Corollary 3.1 (ii) is an analog of Granirer [4, Theorem 4, p. 20] for topological semigroups.

B. Evolution and convolution of bounded linear functionals. Let $S$ be a topological semigroup and let $X$ be a left (right) translation 
invariant, left (right) introverted closed subspace of $C B(S)$. Following Pym [11] and Day [2] for $m$ and $n$ in $X^{*}$, let $m \odot n$ (resp. $m * n$ ) be the evolution (resp. convolution) of $m$ and $n$ defined by $m \odot n(f)=$ $m\left(n_{l} f\right)\left(m * n(f)=n\left(m_{r} f\right)\right)$ for $f$ in $X$. Notice that evolution here is the same as Arens product in Day [2]. In term of evolution and convolution Theorem 2.2 implies the following:

CoROLlary 3.2. (i) Let $S, X, \bar{\mu}$, and $m$ be as in Theorem 2.2 (i) (resp. (ii)), then $\bar{\mu} * m=\bar{\mu} \odot m$ on $X$.

(ii) Let $S, X, n$, and $m$ be as in Theorem 2.2 (iii), then $n * m=$ $n \odot m$.

REMARKS. 1. Corollary 3.2 (i) implies that the bilinear mapping $(\mu, m) \in M(S) \times X^{*} \rightarrow \bar{\mu} \odot m \in X^{*}$ is separately continuous where $M(S)$ is equipped with $\sigma(M(S), T X)$ topology and $X^{*}$ with weak * topology. Similar assertion holds by applying part (ii). In particular in this way one gets the weakly almost periodic compactification of a topological semigroup. (See also Pym [12].)

2. Let $S$ be a completely regular $D$-space semigroup and $\mu$ and $\nu$ elements of $M_{\sigma}(S)$. Then Corollary 3.2 (i) implies that

$$
\begin{aligned}
\bar{\mu} \odot \bar{\nu}(f) & =\bar{\mu}\left(\bar{\nu}_{l} f\right)=\int \bar{\nu}_{l} f d \mu=\iint f(t s) d \nu(s) d \mu(t) \\
& =\bar{\mu} * \bar{\nu}(f)=\bar{\nu}\left(\bar{\mu}_{r} f\right)=\int \bar{\mu}_{r} f d \nu=\iint f(t s) d \mu(t) d \nu(s)
\end{aligned}
$$

for each $f$ in $L U C(S)$. This is an analog of Glicksberg [2, Theorem 3.1]. Note that this observation deserves more attention and may lead to a suitable way of defining the convolution of Baire measures. (See also $[6,19.23(\mathrm{~b})]$.)

\section{REFERENCES}

1. R. B. Burckel, Weakly Almost Periodic Functions on Semigroups, Gordon and Breach, New York, 1970.

2. M. M. Day, Amenable semigroups, Illinois J. Math., 1 (1957), 509-544.

3. I. Glicksberg, Weak compactness and separate continuity, Pacific J. Math., 11 (1961), 205-214.

4. E. Granirer, On Baire measure on D-topological spaces, Fund. Math., 60 (1967), 1-22.

5. F. P. Greenleaf, Invariant means on topological groups and their applications, Van Nostrand, Princeton, N. J., 1969.

6. E. Hewitt and K. A. Ross, Abstract Harmonic Analysis I. Springer Verlag, BerlinGottingen-Heidelberg, 1963.

7. A. Hulanicki, Means and Folner condition on locally compact groups, Studia Math., 27 (1966), 87-104.

8. H. Kharaghani, Left thick subsets of a topological semigroup, Illinois J. Math., 22 (1978), 41-48.

9. P. Milnes, Compactification of semitopological semigroups, J. of Aust. Math. Soc., 
Volume XV, Part 4 (1973), 488-503.

10. I. Namioka, On a recent theorem by Reiter, Proc. Amer. Math. Soc., 17 (1966), 1101-1102.

11. J. S. Pym, The convolution of linear functionals, Proc. London Math. Soc., (3), 14 (1964), 431-444.

12. The convolution of functionals on spaces of bounded functions, Proc. London Math. Soc., (3), 15 (1965), 84-104.

13. W. Rudin, Functional Analysis, Tata McGraw-Hill, New Delhi, 1974.

Received May 3, 1977 and in revised form January 4, 1978.

Pahlati University

SHIRAZ, IraN 


\title{
PACIFIC JOURNAL OF MATHEMATICS
}

\section{EDITORS}

RICHARD ARENS (Managing Editor)

University of California

Los Angeles, CA 90024

Charles W. Curtis

University of Oregon

Eugene, OR 97403

C. C. MOORE

University of California

Berkeley, CA 94720

\section{J. DUGUNDJI}

Department of Mathematics University of Southern California Los Angeles, CA 90007

R. Finn and J. Milgram

Stanford University

Stanford, CA 94305

\section{ASSOCIATE EDITORS}
E. F. BECKENBACH
B. H. NeumanN
F. WOLF
K. YOSHIDA

\section{SUPPORTING INSTITUTIONS}

\author{
UNIVERSITY OF BRITISH COLUMBIA \\ CALIFORNIA INSTITUTE OF TECHNOLOGY \\ UNIVERSITY OF CALIFORNIA \\ MONTANA STATE UNIVERSITY \\ UNIVERSITY OF NEVADA, RENO \\ NEW MEXICO STATE UNIVERSITY \\ OREGON STATE UNIVERSITY \\ UNIVERSITY OF OREGON
}

\author{
UNIVERSITY OF SOUTHERN CALIFORNIA \\ STANFORD UNIVERSITY \\ UNIVERSITY OF HAWAII \\ UNIVERSITY OF TOKYO \\ UNIVERSITY OF UTAH \\ WASHINGTON STATE UNIVERSITY \\ UNIVERSITY OF WASHINGTON
}

The Supporting Institutions listed above contribute to the cost of publication of this Journal, but they are not owners or publishers and have no responsibility for its content or policies.

Mathematical papers intended for publication in the Pacific Journal of Mathematics should be in typed form or offset-reproduced, (not dittoed), double spaced with large margins. Please do not use built up fractions in the text of the manuscript. However, you may use them in the displayed equations. Underline Greek letters in red, German in green, and script in blue. The first paragraph or two must be capable of being used separately as a synopsis of the entire paper. Items of the bibliography should not be cited there unless absolutely necessary, in which case they must be identified by author and journal, rather than by item number. Manuscripts, in triplicate, may be sent to any one of the editors. Please classify according to the scheme of Math. Reviews, Index to Vol. 39. All other communications should be addressed to the managing editor, or Elaine Barth, University of California, Los Angeles, California, 90024.

50 reprints to each author are provided free for each article, only if page charges have been substantially paid. Additional copies may be obtained at cost in multiples of 50 .

The Pacific Journal of Mathematics is issued monthly as of January 1966. Regular subscription rate: $\$ 72.00$ a year (6 Vols., 12 issues). Special rate: $\$ 36.00$ a year to individual members of supporting institutions.

Subscriptions, orders for numbers issued in the last three calendar years, and changes of address should be sent to Pacific Journal of Mathematics, P.O. Box 969, Carmel Valley, CA 93924, U.S.A. Older back numbers obtainable from Kraus Periodicals Co., Route 100, Millwood, NY 10546.

PUBLISHED BY PACIFIC JOURNAL OF MATHEMATICS, A NON-PROFIT CORPORATION

Printed at Kokusai Bunken Insatsusha (International Academic Printing Co., Ltd.). 8-8, 3-chome, Takadanobaba, Shinjuku-ku, Tokyo 160, Japan.

Copyright (C) 1978 by Pacific Journal of Mathematics Manufactured and first issued in Japan 


\section{Pacific Journal of Mathematics \\ Vol. 78, No. $2 \quad$ April, 1978}

Su-Shing Chen, Weak rigidity of compact negatively curved manifolds .... 273

Heinz Otto Cordes and D. A. Williams, An algebra of pseudodifferential operators with nonsmooth symbol ....................... 279

Herbert Paul Halpern, Normal expectations and integral decomposition of type III von Neumann algebras ......................... 291

G. Hochschild, On representing analytic groups with their

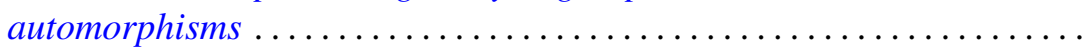

Dean G. Hoffman and David Anthony Klarner, Sets of integers closed under affine operators - the closure of finite sets ....................

Simeon Ivanov, On holomorphic relative inverses of operator-valued

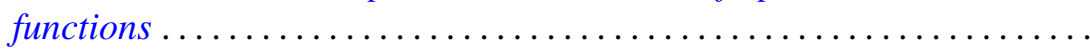

O. P. Juneja and M. L. Mogra, Radii of convexity for certain classes of

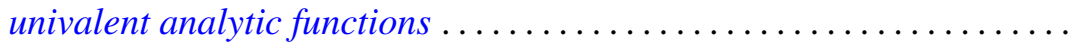

Hadi Kharaghani, The evolution of bounded linear functionals with application to invariant means.......................... 369

Jack W. Macki, A singular nonlinear boundary value problem .......... 375

A. W. Mason and Walter Wilson Stothers, Remarks on a theorem of $L$. Greenberg on the modular group ........................ 385

Kevin Mor McCrimmon, Peirce ideals in Jordan algebras . . . . . . . . . . . 397

John C. Morgan, II, On the absolute Baire property ................ 415

Gerard J. Murphy, Commutative non-Archimedean $C^{*}$-algebras ...

Masafumi Okumura, Submanifolds with L-flat normal connection of the

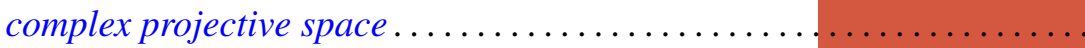

Chull Park and David Lee Skoug, Distribution estimates of barrier-crossing probabilities of the Yeh-Wiener process ...............

Irving Reiner, Invariants of integral representations ........

Phillip Schultz, The typeset and cotypeset of a rank 2 abelian group ..... 503

John Brendan Sullivan, Representations of Witt groups ....

Chia-Chi Tung, Equidistribution theory in higher dimensions . . . 